\title{
Towards automated evaluation of left atrial transit time
}

\author{
Yongpeng Tang, Michael Passick, Jie J Cao, Yi Wang ${ }^{*}$ \\ From 17th Annual SCMR Scientific Sessions \\ New Orleans, LA, USA. 16-19 January 2014
}

\section{Background}

Left atrial transit time (LATT) has potential to approximate left ventricular end diastolic pressure noninvasively. Small artifacts are often present in the down-slope portion of the time-intensity curve most likely due to poor SNR resulting from relatively low contrast dosing. While easily circumvented by experienced operator the artifact presents a challenge to automated detection of area under the curve (AUC) which is essential in the determination of LATT. To minimize user interface we sought to develop a filtering algorithm in the post processing and compared automated AUC detection with operator directed AUC assessment.

\section{Methods}

Thirty seven patients (age: $54.1 \pm 15.3$, 9 females) were studied. All subjects underwent first pass perfusion using the SSFP saturation recovery sequence with ECG gating and breath-hold during gadolinium bolus injection at $0.01 \mathrm{mmol} / \mathrm{kg}$. A time-intensity curve was generated by tracing and plotting the blood signals in the left atrium including all image phases and processed in a custom Matlab program with and without the filtering algorithm. The unfiltered and filtered AUC were compared to the operator directed assessment. The example in Figure 1 shows a time-intensity curve from unfiltered data. Without filtering the AUC ended at phase 52 due to an artifact, while a filtered program detected AUC up to phase 60 which coincided with the AUC assessed by an experienced operator.

\section{Results}

Of the 37 cases analyzed, artifacts were present in 18 cases. The filtering algorithm was successful at detecting and removing artifacts in all 18 cases. As a result, the

Research and Education, St. Francis Hospital, Roslyn, New York, USA

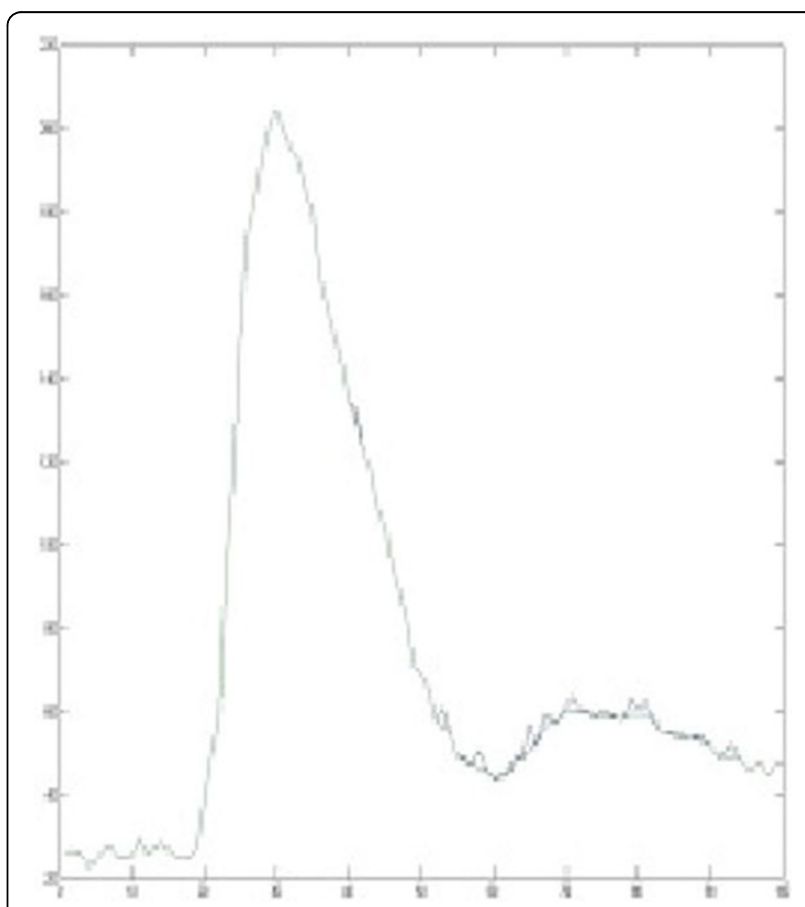

Figure 1 Shows an example of original and filtered curves.

filtered AUC was much closer to the operator directed AUC shown (in green and in red, respectively) in Figure 2 than unfiltered AUC (in blue) was. Bland-Altman analysis demonstrated a much improved agreement between filtered and operator directed AUC detection (Figure 4) than filtered and unfiltered AUC (Figure 3).

\section{Conclusions}

Artifact is common in time-intensity curve of the LA blood signal. A filtering algorithm in the post process is promising to successfully remove the artifact allowing automated assessment of AUC. 


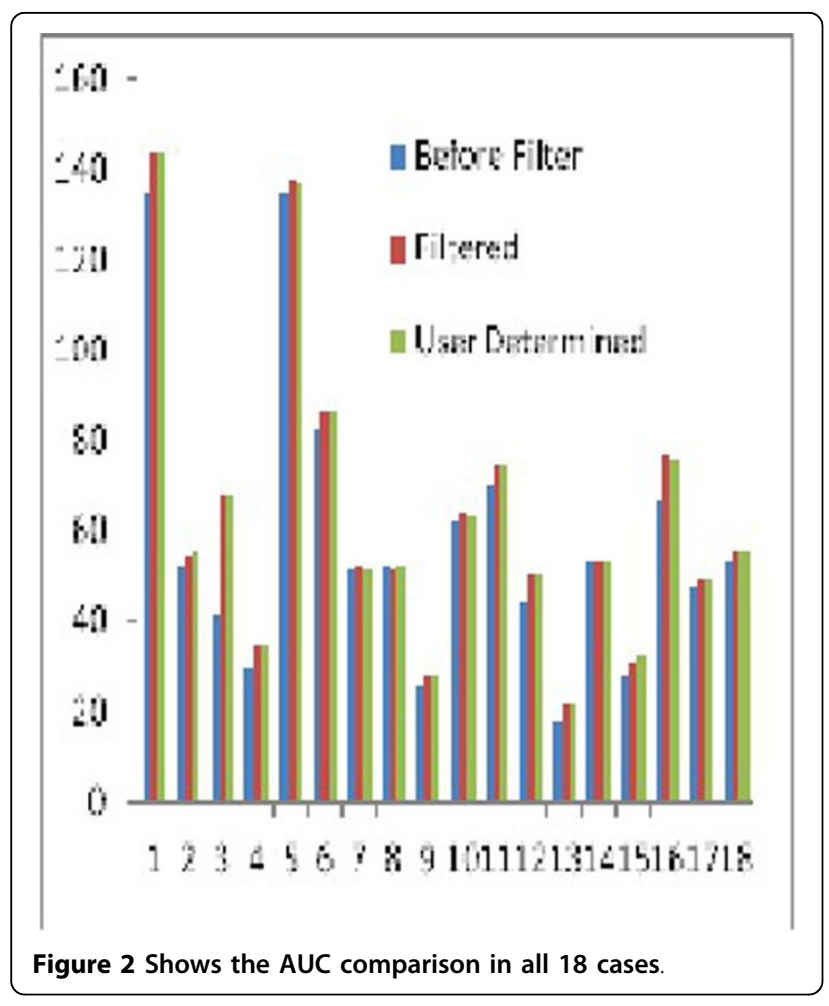

Figure 2 Shows the AUC comparison in all 18 cases.

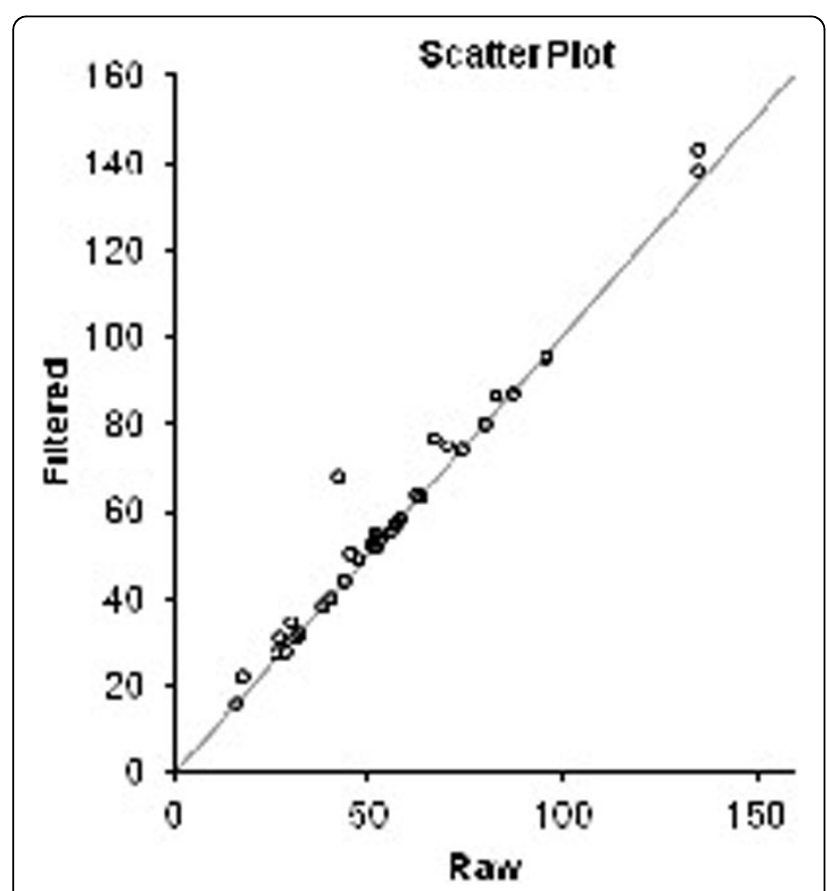

Figure 3 (left) Shows the Bland Altman plot of filtered versus unfiltered AUC.

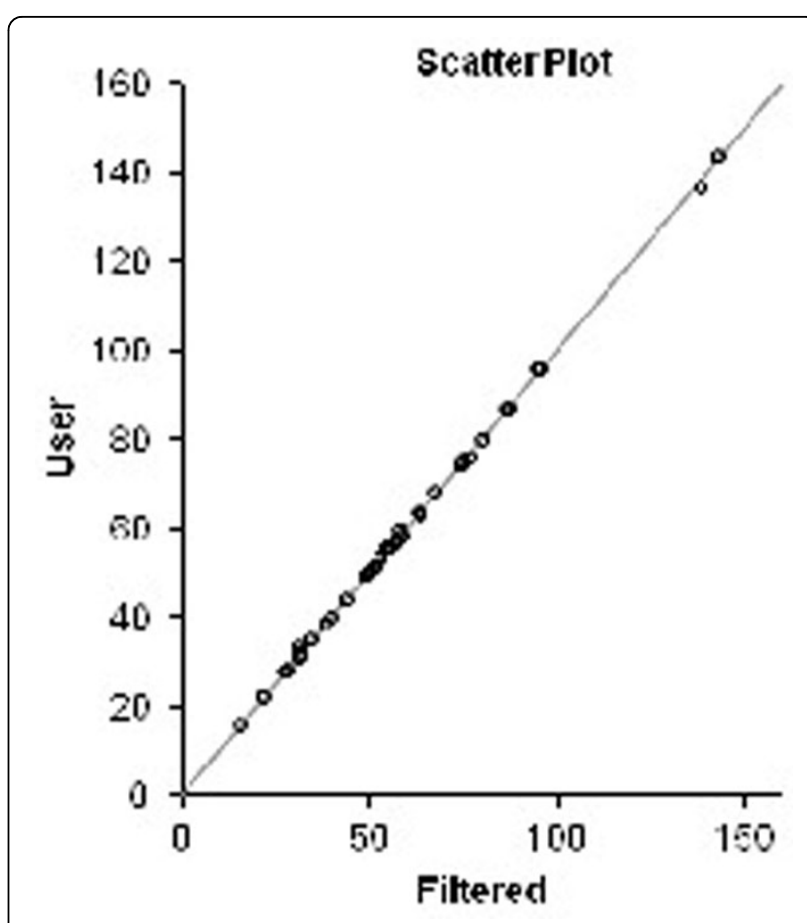

Figure 4 (right) Shows the Bland Altman plot of filtered versus operator directed AUC

\section{Funding}

None.

Published: 16 January 2014

doi:10.1186/1532-429X-16-S1-P36

Cite this article as: Tang et al:: Towards automated evaluation of left

atrial transit time. Journal of Cardiovascular Magnetic Resonance 201416

(Suppl 1):P36.

Submit your next manuscript to BioMed Central and take full advantage of:

- Convenient online submission

- Thorough peer review

- No space constraints or color figure charges

- Immediate publication on acceptance

- Inclusion in PubMed, CAS, Scopus and Google Scholar

- Research which is freely available for redistribution 